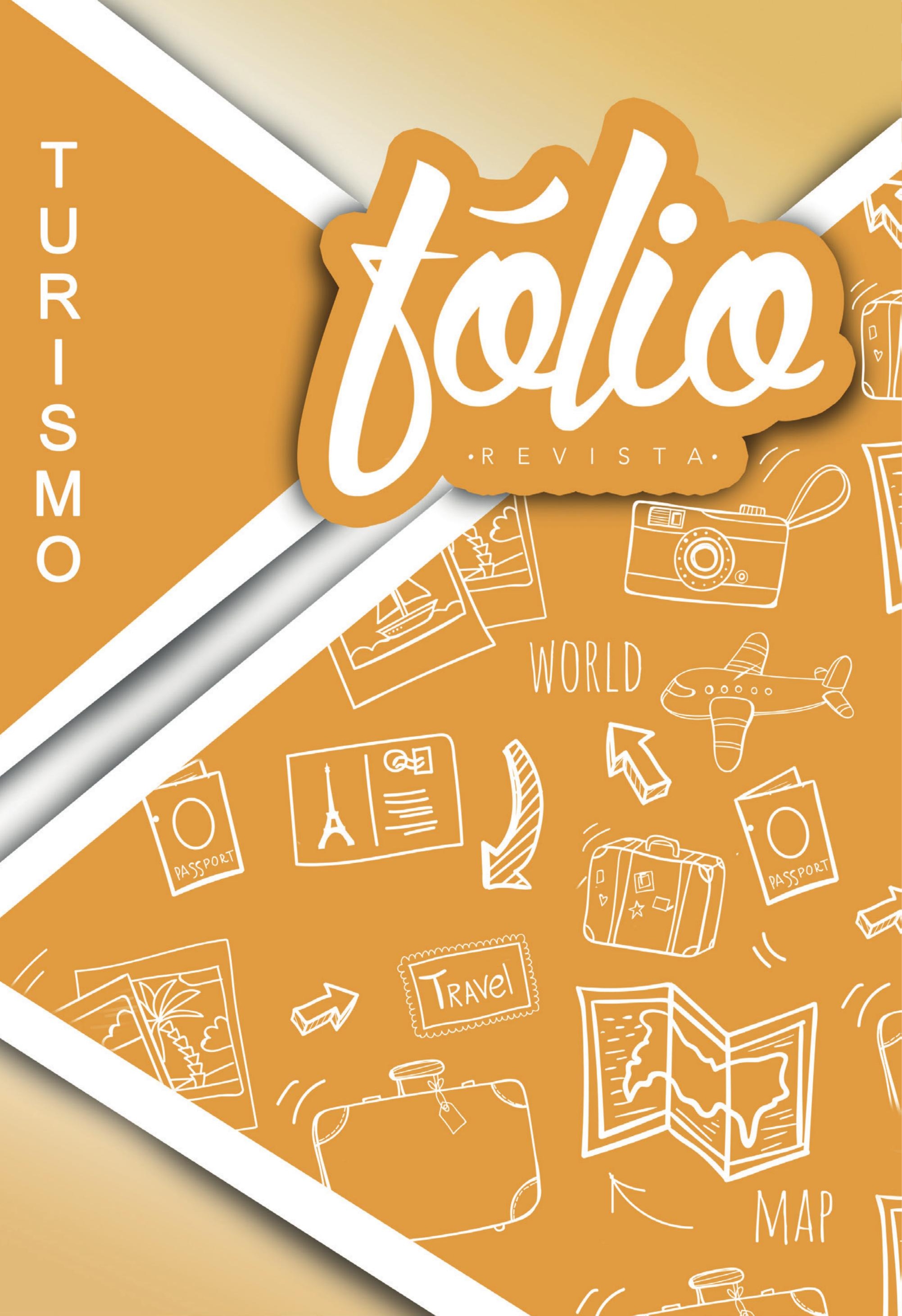




\section{O impacto das viagens internacionais na formação do turismólogo: um estudo de caso dos alunos e ex alunos do curso de Turismo do Centro Universitário Metodista IPA}

The impact of international travels in tourismologist performance: a case study of students and former students of Tourism undergraduate course from Methodist University Center IPA

\section{Alberto Macagnan \\ Guilherme Bridi}

\section{Resumo}

O presente trabalho tem por objetivo analisar e apresentar elementos que forneçam embasamento para a discussão sobre a importância das viagens, bem como fazer um comparativos dos alunos que viajaram e os que ainda não tiveram esta oportunidade nas categorias domínio de idiomas, colocação no mercado, faixa salarial e planejamento pessoal de viagens futuras. Utilizando-se de métodos de estudo de caso com pesquisa quantitativa, a coleta de dados compreendeu a aplicação de questionários presenciais com alunos e ex alunos do curso de bacharelado em turismo do IPA, entre os meses de Agosto e Setembro de 2017. Após o levantamento dos dados, os mesmos foram comparados e com o resultado, consta-se a existência de muitas similaridades nas categorias que envolvem o domínio de idiomas e colocação no mercado, ao passo que as categorias de faixa salarial e planejamento pessoal de viagens futuras apresentaram consideráveis distinções entre os grupos pesquisados.

Palavras-chave: Turismo. Viagens. Formação. Turismólogos.

\section{Abstract}

The purpose of this paper is to analyze and present elements that provide a basis for the discussion about the importance of international travel. This theme concerns how travel and tourism can parallel way from the historical context of the GRAND TOUR, to the present day that served as the basis for the construction of the theoretical reference. Using case study methods with qualitative research, the data collection included the application of face-to-face questionnaires with students and former students of the bachelor's degree in IPA tourism, between August and September 2017. After the survey of the data, they were compared and with the result, there are many similarities in the language domain and placement categories, while the categories of salary range and personal planning of future trips presented considerable distinctions among the groups surveyed.

Keywords: Tourism. Travels. Performance. Turismologists. 


\section{Introdução}

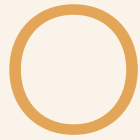

tema deste trabalho contempla o impacto das viagens na formação do turismólogo, a partir de uma análise das similaridades e diferenciações de perfil de estudantes de turismo que realizam viagens ao exterior com aqueles que ainda não possuem esta etapa cumprida em seu currículo. Foram consideradas as seguintes categorias: domínio de idiomas, colocação no mercado, faixa salarial e planejamento pessoal. A pesquisa foi aplicada entre os meses de Agosto e Setembro de 2017 com amostra de 40 alunos e ex alunos do Curso de Turismo do IPA, sendo que a amostra foi dividida igualmente entre estudantes que já realizaram viagem e aqueles que ainda não tiveram essa oportunidade.

O problema da pesquisa buscava responder a seguinte questão: Partindo do pressuposto de que as experiências adquiridas na viagens constituem-se como elementos que contribuem para a qualificação da formação do turismólogo, pergunta-se: Que elementos de semelhança e diferença no tocante as categorias domínio de idiomas, colocação no mercado, faixa salarial e planejamento pessoal de viagens futuras compõem o perfil profissional de um turismólogo que já realizou viagem ao exterior, com aquele que ainda não teve essa oportunidade?

O objetivo geral foi contribuir para o debate que envolve as viagens internacionais como um elemento de qualificação da formação do turismólogo, em especial no tocante as categorias domínio de idiomas, colocação no mercado, faixa salarial e planejamento pessoal de viagens futuras.

Como objetivos específicos, têm-se: Identificar os principais empecilhos à realização de viagens ao exterior por parte dos estudantes de turismo; Apresentar e analisar pontos de semelhanças e diferenças no perfil dos dois grupos de entrevistados sob as categorias domínio de idiomas, colocação no mercado, faixa salarial e planejamento pessoal de viagens futuras.

Em se tratando das raízes históricas, as viagens constituem-se como elementos essenciais para a formação e qualificação profissional desde à época do Renascimento, com o advento do Grand Tour. (BARRETTO, 2006). Essa modalidade de viagens possuía como característica principal ampliar a visão de mundo do viajante, tornando- o capaz de prover melhores contribuições para o exercício de sua função profissional. (REJOWSKI et al, 2005).

Ao trazermos o enfoque sobre o profissional do setor turístico com ensino superior na área, Bridi e Santos (2012) destacam a necessidade constante em se repensar as competências e habilidades propostas na formação desse profissional, para que o mesmo possa, justamente, estar apto a atender à demanda do perfil profissional do século XXI.

Dessa forma, justifica-se a relevância de pesquisar esse tema, uma vez que as viagens de formação poderão constituir-se em elementos favorecedores dessas competências necessárias ao turismólogo da contemporaneidade, contribuindo, igualmente, para uma melhoria na qualificação dos produtos e serviços turísticos.

Pessoalmente, o pesquisador pretende com este trabalho, contribuir com pertinência ao futuro turismólogo sobre a importância das viagens internacionais para o sucesso de sua carreira e, com isso, beneficiar diretamente aqueles que farão uso de seus conhecimentos obtido in loco. Parece possível compreender que, com isso, constata-se a possibilidade de desenvolver um novo nicho de trabalho para o profissional do Turismo, e consequentemente usufruir de recursos e benefícios que a profissão proporciona.

\section{Referencial teórico}

\section{A importância das viagens de estudo - contexto histórico do Grand Tour}

Conforme mencionado na justificativa, pode-se considerar que o modelo de valorização das viagens como requisito para qualificação profissional teve sua gênese na Europa, durante o período do Renascimento, com a prática do Grand Tour.

Dessa forma, de acordo com Rejowski et. al. (2005), o modelo renascentista europeu caracterizou-se, basicamente, pela melhoria da produtividade agrícola, ressurgimento das cidades, bem 
como o desenvolvimento das formas de comércio de negócios, com a exploração do mundo recém descoberto e os avanços nos campos das artes, literatura e da ciência moderna.

Essa busca incessante pelo conhecimento imediato, característica da era moderna, tinha como um de seus princípios a lógica do humanismo científico, conforme os apontamentos de Barbosa (2005). Para os homens das elites da época, dentre as formas de se conhecer o mundo que os cercava, estavam as viagens.

.Ainda com relação às tendências das viagens da modernidade, em se tratando do contexto da classe nobre dominante britânica, predominava a tipologia de viagens Grand Tour, o qual, para Rejowski et. al. (2005, p.38), "tinha por intuito desenvolver, através da educação, a formação qualificada de novos estadistas e embaixadores. Dentre os principais destinos visitados estavam França e Itália."

Conforme Rejowski et. al. (2005):

Para completar sua educação, os jovens ingleses viajavam por toda a Europa em companhia dos seus tutores. A prática continuou a se desenvolver nos séculos XVII e XVIII, até se tornar uma moda entre as ricas famílias inglesas. A educação dos nobres não era considerada completa, a menos que eles passassem de um a três anos viajando pela Europa, com um tutor. (REJOWSKI et. al., 2005, p. 38).

Corroborando nessas questões, Sodré (2010, p.28) reforça que "historicamente, a Itália já era o destino de muitos viajantes desde o século XVII, quando a prática do Grand Tour aristocrático se consolidou na Europa, sobretudo entre intelectuais, filósofos e artistas provenientes da Inglaterra, Alemanha e França."

Conforme Avena (2008):

[...] o Grand Tour, termo surgido em 1670, era uma viagem da elite animada pela vontade de conhecer melhor o mundo: os lugares, os povos a fim de desenvolver sua personalidade, considerado como uma pedagogia do Humanismo, uma incitação a refletir sobre o imaginário. Nessa viagem, se descobre a sociedade, a ciência e o mundo chegando-se à construção social de um espaço intelectual. As expectativas sociais desse tipo de viagem eram a formação cultural de um meio pela descoberta das artes, de sua herança magnificada e, por aquelas dos usos e costumes. Além disso, como uma exigência de status cultural e social, aglutinava necessidades educativas e políticas diversas: ela contribuía para a formação do homem de Estado, do homem do mundo, do homem sensível (AVENA, 2008, p. 301).

Para Bridi e Santos (2012), citando Barretto (2006), essa nova tendência de viagens de jovens acompanhados de seu professor particular se caracterizava como um antecedente do turismo da forma como conhecemos atualmente, reiterando, que, em tais viagens, não ocorria propriamente o turismo, mas sim os tours ${ }^{1}$ e que etapa, para determinados historiados, foi denominada de "barroca".

Com base nas concepções acima, parece possível considerar que muitos elementos observados nas características do Grand Tour se assemelham aos dias de hoje, em especial no que se refere à ampliação da visão de mundo, contato com outras culturas, no domínio de uma segunda língua, obtida a partir de uma experiência de viagem internacional.

Naturalmente, é importante ressaltar que, um dos principais desafios da atualidade no que se refere este tópico seria proporcionar que as classes menos favorecidas também tivessem acesso a este tipo de formação específica, em especial, os estudantes de ensino superior na área do Turismo, justamente para que os mesmos possam desenvolver e ampliar sua visão de mundo, sendo esta uma das competências essenciais para o exercício pleno da profissão.

\section{A importância das viagens para a formação profissional na contemporaneidade}

Num primeiro momento, há que se ponderar que, diante do contexto da atualidade, muitos são

\footnotetext{
1 Viagens de ida e volta, realizadas pela classe dominante da época. (BARRETTO, 2006, P.39)
} 
os desafios e processos que envolvem prover uma formação qualificada aos profissionais de turismo. Sem desconsiderar a importância de todos esses aspectos, será dado enfoque, neste trabalho, para as viagens internacionais como uma ferramenta de qualificação da formação de profissionais.

Dessa forma, em uma abordagem mais contemporânea sobre a importância das viagens para a formação profissional, Carvalho (2009) assinala que, em se tratando da profissionalização em diferentes setores, observa-se a exigência de domínio técnico e conceitual da área na qual atuam, conhecimento de idiomas e culturas de outros grupos, assim como de tecnologias da informação e comunicação, e disponibilidade de deslocamento do local de origem para qualquer outra cidade, estado, país ou continente.

Nessa linha, para Pilatti e Santos (2008), o processo de rompimento de fronteiras atualmente presente na sociedade proporciona o surgimento de desafios e ocasiona mudanças mais velozes, tornado o mercado de trabalho cada vez mais competitivo. Isso posto, constata-se igualmente que as exigências se tornam cada vez maiores e os profissionais devem ser cada vez mais capacitados para destacarem-se nesse novo mundo, reunindo assim condições de se inserir efetivamente nesse contexto globalizado.

Para Souza (s/a) a relevância do turismo na economia global traz consigo a necessidade de formação de profissionais aptos a enfrentarem os desafios que são inerentes ao setor. Nesse sentido, a formação de recursos humanos com competências efetivas para atuarem em diferentes setores da atividade turística constitui-se como um elemento essencial nesse cenário.

Como uma forma de contribuir para essa processo de formação profissional, se inserem a ideia das viagens, sob diferentes naturezas. Conforme os apontamentos de Bridi, Prisco e Vieira (2018), citando Beni (2001), as viagens com cunho educativo se espalharam pelo continente europeu e pelos EUA, sendo adotadas por instituições particulares. No cenário brasileiro estas práticas foram adotadas por colégio de elite e consistiam em viagens com acompanhamento de professores, visitando locais históricos e com a realização de aulas sobre esses. Versando o enfoque dessa realidade no que concerne às políticas públicas, pode-se destacar a criação do programa governamental Ciência Sem Fronteiras, o qual oferecia bolsas de mobilidade acadêmica para estudantes de diferentes áreas do conhecimento (não contemplava o Turismo), a partir de acordos e parcerias com diversas instituições de ensino, para programas de intercâmbio e de pesquisa. $\bigcirc$ referido programa teve forte apoio dos Estados Unidos e demais países os quais possuíam acordos de cooperação acadêmica com Brasil, tal como Portugal e Espanha. (SILVA, 2012). Nesse sentido, a previsão inicial do programa era oferecer cerca de 100 mil bolsas de estudos em 04 anos para alunos, professores, técnicos e pesquisadores dos cursos de graduação e pós graduação no país. (CASTRO, et al., 2012) O referido programa teve suas atividades interrompidas no início de 2017, em decorrência no momento de austeridade por qual passa a economia (e a política) brasileira.

Nesse sentido Pilatti e Santos (2008), pode-se constatar que o domínio de um segundo idioma pode constituir-se uma das competências e habilidades que favoreçam os profissionais da atualidade, em especial, através de sua remuneração, a qual segundo os autores, poderá ser entre 30 a $45 \%$ superior em relação a profissionais que não possuam fluência num segundo idioma.

Segundo Souza (s/a), as viagens técnicas, enquanto instrumentos de aprendizagem consubstanciadas nas vivências de experiências estão longe de serem atividades do curso desprovidas de propósitos definidos, tão pouco são percebidas como atividades impeditivas para o seu desempenho acadêmico natural e concomitantemente ao longo do curso.

Nessa mesma linha, no tocante à importância das experiências internacionais para formação, observa-se as considerações do O Ministério do Turismo do Brasil (2010, s/p)

\footnotetext{
"A educação internacional teve o seu valor ampliado nos últimos anos, passando a ser prioridade na agenda institucional de diversos países. Adquirir experiência internacional faz parte dos planos de milhares de estudantes de diferentes idades, níveis acadêmicos e de todos os lugares do mundo".
} 
Corroborando nestas questões Carvalho (2009) sinaliza que as viagens devem assumir a função de espaço de aprendizado crítico da realidade, na condição de processo de investigação e conhecimento, propiciando observação, comparação e produção de diferentes formas de criar, sistematizar e difundir manifestações culturais.

Segundo Carvalho (2009):

Considera ainda que as viagens culturais, uma vez subvencionadas e vinculadas a uma instituição universitária, se configuram igualmente em viagens pedagógicas, ainda que permeadas por momentos lúdicos, exigem rigor na organização, na escolha dos roteiros, no tempo de permanência nos locais, nas formas disponíveis para apropriação de informações sobre a realidade de cada espaço, seus profissionais e seu público, sua história, seus mantenedores. Solicitam preparo anterior do grupo sobre os lugares e eventos que encontrarão, para que já possuam subsídios, os quais facilitarão a metabolização das experiências ali adquiridas e sua re-significação e incorporação em suas formações pessoais, culturais e profissionais de cada nível de ensino. (Carvalho, 2009, p. 30).

Nesse sentido, Souza (s/a) destaca a necessidade de um conhecimento prático no contexto do turismo, na medida em que possibilita que as metodologias de ensino e aprendizagem desempenhem um papel importante na educação da área. Assim sendo, ao envolverem-se com atividades de viagens técnicas de formação e qualificação, os estudantes não apenas observam, registram e interpretam com base no contexto em que estão inseridos, como também realizam funções interativas com seus colegas, professores, com os profissionais do setor do turismo, com os turistas, com a própria comunidade de sua residência ou dos destinos a visitar e com o mundo exterior à instituição de ensino, obtendo, assim, a ampliação de sua visão de mundo, tal como era o objetivo do Grand Tour ( BARRETTO, 2006).

Dessa forma, considera-se que as afirmações de Souza (s/a) tencionam, para a ideia de viagem técnica como instrumento de aprendizagem através da vivência direta de experiências, sendo este um componente fundante da formação de profissionais que estudam o turismo em nível superior. O referido autor, citando Souza (2014) argumenta ainda que as viagens técnicas que envolvem saídas de campo com pernoite no destino tem se configurado componentes obrigatórios na estrutura curricular dos cursos superiores de Turismo sendo, configurando-se, assim, em elementos adicionais e opcionais da formação dos estudantes.

Entretanto, observa-se igualmente a existência de correlações entre a realidade atual com aquela observada no Grand Tour, a qual remete para a questão que, apesar de se terem providos muitos avanços no sentido de popularizar as viagens e experiências internacionais, infelizmente esse é considerado ainda um privilégio restrito a pouco estudantes, o que pode configurar num elemento pernicioso ao desenvolvimento de uma formação adequada em turismo de nível superior. A suspensão e redução de programas governamentais de bolsas de estudo no exterior também é um indicativo de que as viagens internacionais dos estudantes ficarão mais restritas nos próximos anos, o que demanda por sua vez, a necessidade, por parte dos gestores de educação superior em turismo no Brasil, em se buscar desenvolver soluções e opções que possibilitem uma reconfiguração do cenário acima citado, proporcionando aos estudantes caminhos que contribuam para a compreensão da importância de uma experiência internacional como integrante diferencial de seu currículo profissional.

\section{Metodologia}

O método utilizado por este trabalho foi o Estudo de Caso, de natureza quantitativa. A técnica de pesquisa utilizada para coleta de dados foi a de entrevista padronizada.

Segundo o autor, Yin (2010, p. 24) na obra Estudo de Caso - Planejamento e Métodos, "o estudo de caso é usado em muitas situações, para contribuir ao nosso reconhecimento dos fenômenos individuais, grupais, organizacionais, sociais, políticos e relacionados."

Conforme Gil (2007), a pesquisa qualitativa 
possui como intuito central promover uma verificação dos dados de uma forma subjetiva, procurando ir além dos índices estatísticos e matemáticos.

A coleta de dados compreendeu as seguintes etapas: aplicação de formulário de entrevista de forma presencial nos meses de Agosto e Setembro de 2017, com amostra de 40 alunos e ex-alunos do Curso Superior em Turismo do IPA (20 que viajaram e 20 que não viajaram) e análise de indicadores de divulgação obtidos através de
Banco de Dados.

A entrevista foi realiza na própria sala de aula, com os alunos matriculados no curso, em relação aos ex alunos foram contatados por telefone e posteriormente, indo ao seu encontro para formalizar a entrevista.

Não houve dificuldades em realizar a referida entrevista pois o pesquisador além de conhecer o grande grupo realizou quase todas as viagens propostas pelo curso de Turismo do IPA.

\section{Apresentação dos resultados e análise de dados}

Conforme descrito na Metodologia, a pesquisa foi aplicada com amostra de 20 alunos que participaram das Missões Internacionais do Curso e outros 20 alunos os quais não realizaram a referida atividade.

A escolha dos alunos foi aleatória, perguntando antes se aviam viajado ou não.

Dessa forma, serão abaixo apresentados, primeiramente, os resultados referentes ao grupo que já viajou.

\section{Apresentação de dados: grupo que viajou - questionário A}

Segue abaixo a apresentação dos resultados obtidos através do instrumento de coleta de dados.

Tabela 1 - Questão 1: idade

\begin{tabular}{|c|c|c|}
\hline Respostas & Quantidade & Percentual \\
\hline 18 a 21 anos & 5 & $45 \%$ \\
\hline 22 a 25 anos & 9 & $30 \%$ \\
\hline 26 a 30 anos & 6 & $0 \%$ \\
\hline Acima 30 & 0 & $100 \%$ \\
\hline Total & 20 & $0 \%$ \\
\hline
\end{tabular}

Fonte: Elaborado pelo autor

Na Tabela 1, foi possível observar que os entrevistados são todos jovens, até 30 anos de idade, com maior incidência (45\%), para jovens entre 22 e 25 anos. O público entre 26 e 30 anos compreende $30 \%$ e o público entre 18 e 21 anos representa $25 \%$ do total.

Tabela 2 - Questão 2: Em qual(is) viagem(s) do curso participaste?

\begin{tabular}{|c|c|c|}
\hline Respostas & Quantidade & Percentual \\
\hline Uruguai - 2011 & 3 & $9,6 \%$ \\
\hline Argentina - 2012 & 2 & $6,4 \%$ \\
\hline México - 2013 & 3 & $9,6 \%$ \\
\hline EUA - 2014 & 6 & $19,3 \%$ \\
\hline Colômbia - 2015 & 6 & $19,3 \%$ \\
\hline México - 2016 & 11 & $35,8 \%$ \\
\hline
\end{tabular}


Na tabela 2, foi possível observar que os entrevistados, na sua grande maioria, viajaram para o México em 2016, com 35,8\% seguido por Colômbia em 2015 e EUA 2014 com 19,3\%, México 2013 e Uruguai 2011 com 9,6\%, e finalmente a Argentina com 6,4\% em 2012.

Tabela 3 - Questão 3: Em sua opinião, qual a importância das viagens internacionais para a sua formação?

\begin{tabular}{|c|c|c|}
\hline \multicolumn{1}{|c|}{ Resposta } & Quantidade & Percentual \\
\hline Essencial & 12 & $25 \%$ \\
\hline Muito importante & 5 & $10 \%$ \\
\hline Importante & 2 & $5 \%$ \\
\hline Pouco importante & 1 & $0 \%$ \\
\hline Nada importante & 0 & $0 \%$ \\
\hline
\end{tabular}

Fonte: Elaborado pelo autor

Na tabela 3, 60\% dos entrevistados afirmaram que as viagens internacionais são essenciais na formação do turismólogo seguido por 25\% achando muito importante, 10\% importante e somente 5\% achando pouco importante, e nenhum entrevistado respondeu ser nada importante.

Tabela 4 - Questão 4: Em sua opinião quais os principais motivos (problemas) que não te permitem viajar mais?

\begin{tabular}{|c|c|c|}
\hline \multicolumn{1}{|c|}{ Resposta } & Quantidade & Percentual \\
\hline Fator financeiro & 19 & $55 \%$ \\
\hline Fator tempo & 01 & $5 \%$ \\
\hline $\begin{array}{c}\text { Não gosta da proposta } \\
\text { das viagens do curso }\end{array}$ & 0 & $0 \%$ \\
\hline
\end{tabular}

Fonte: Elaborado pelo autor

$\mathrm{Na}$ tabela 4, O fator financeiro com 95\%, foi apontado como o motivo pelo qual impede o entrevistado de viajar, seguindo com $5 \%$ respondendo como ser o fator tempo, e ninguém respondeu como sendo a proposta das viagens do curso.

Tabela 5 - Questão 5: Você tem planos de viagem internacional para os próximos 12 meses?

\begin{tabular}{|c|c|c|}
\hline Resposta & Quantidade & Percentual \\
\hline Sim & 14 & $70 \%$ \\
\hline Não & 06 & $30 \%$ \\
\hline
\end{tabular}

Na tabela 5, 70\% dos entrevistados responderam ter um plano de viagem para 2018, e 30\% responderam não terem esse plano. 
Tabela 6 - Questão 6: Qual a sua fluência no idioma Inglês?

\begin{tabular}{|c|c|c|}
\hline Resposta & 02 & $10 \%$ \\
\hline Nenhuma & 11 & $55 \%$ \\
\hline Básico & 05 & $25 \%$ \\
\hline Intermediário & 02 & $10 \%$ \\
\hline Avançado & & $25 \%$.uantidade \\
\hline
\end{tabular}

Fonte: Elaborado pelo autor.

Na tabela 6, com 55\% responderam que sua fluência em inglês é básica, 25\% intermediaria, 10\% não ter nenhuma noção do idioma, e somente $10 \%$ responderam que sua fluência no idioma é avançado.

Tabela 7 - Questão 7: Qual a sua fluência no idioma Espanhol?

\begin{tabular}{|c|c|c|}
\hline Resposta & Quantidade & Percentual \\
\hline Nenhuma & 01 & $5 \%$ \\
\hline Básico & 14 & $70 \%$ \\
\hline
\end{tabular}

Tabela 7 - Questão 7: Qual a sua fluência no idioma Espanhol?

\begin{tabular}{|c|c|c|}
\hline Intermediário & 04 & $20 \%$ \\
\hline Avançado & 01 & $5 \%$ \\
\hline
\end{tabular}

Na tabela 7, com 70\% responderam que sua fluência em espanhol é básica, $20 \%$ intermediaria, $5 \%$ não ter nenhuma noção do idioma, e somente $5 \%$ responderam que sua fluência no idioma é avançado.

Tabela 8 - Questão 8: Você atualmente trabalha no setor de turismo

\begin{tabular}{|c|c|c|}
\hline Resposta & 10 & Percentual \\
\hline Sim & 10 & $50 \%$ \\
\hline Não & $10 \%$ \\
\hline
\end{tabular}

Fonte: Elaborado pelo autor.

Na tabela 8, verificou-se que metade dos entrevistados 50\%, já trabalham no setor de turismo. 
Tabela 9 - Questão 9: Qual a sua faixa salarial média mensal?

\begin{tabular}{|c|c|c|}
\hline \multicolumn{1}{|c|}{ Resposta } & Quantidade & Percentual \\
\hline Até $\mathrm{R} \$ 1.000,00$ & 05 & $05 \%$ \\
\hline De $\mathrm{R} \$ 1.000,00$ a $\mathrm{R} \$ 1.500,00$ & 01 & $40 \%$ \\
\hline De $\mathrm{R} \$ 1.500,00$ a $\mathrm{R} \$ 2.000,00$ & 08 & $05 \%$ \\
\hline De $\mathrm{R} \$ 2.000,00$ a $\mathrm{R} \$ 2.500,00$ & 01 & $25 \%$ \\
\hline Acima de $\mathrm{R} \$ 2.500,00$ & 05 & $25 \%$ \\
\hline
\end{tabular}

Fonte: Elaborado pelo autor.

Na tabela 9, verificou-se que para $40 \%$ dos entrevistados a sua renda é $\mathrm{R} \$ 1.500,00$ a $\mathrm{R} \$ 2.000,00$, para $25 \%$ responderam ser acima de $R \$ 2.500,00,25 \%$ de até $R \$ 1.000,00,5 \%$ de $R \$ 1.000,00$ a $R \$ 1.500,00$ e $5 \%$ também responderam que sua renda é de $R \$ 2.000,00$ a $R \$ 2.500,00$.

Questão 10: Nas questões, solicita-se que seja indicado seu ponto de vista sobre a importância das viagens internacionais para sua formação. Para cada pergunta ou item listado, favor pontuar, sendo 1 nada relevante e 7 muito relevante.

Nesse caso, será aplicado escala de cores para se ilustrar melhor as incidências de respostas.

\section{Nenhuma Incidência}

\section{Uma a cinco incidências}

\section{Seis a dez incidências}

\section{1 a 20 incidências}

Quadro 1 - Resultados Questão 19 - Grupo que já viajou

\begin{tabular}{|c|c|c|c|c|c|c|c|}
\hline Item & 1 & 2 & 3 & 4 & 5 & 6 & 7 \\
\hline Experiência adquirida & $0 \%$ & $0 \%$ & $0 \%$ & $1-5 \%$ & $15 \%$ & $210 \%$ & $1680 \%$ \\
\hline Contato com outras culturas & $0 \%$ & $0 \%$ & $0 \%$ & $0 \%$ & $210 \%$ & $210 \%$ & $1680 \%$ \\
\hline Amadurecimento Profissional & $0 \%$ & $0 \%$ & $210 \%$ & $15 \%$ & $210 \%$ & $420 \%$ & $1155 \%$ \\
\hline Integração entre colegas & $0 \%$ & $0 \%$ & $15 \%$ & $0 \%$ & $210 \%$ & $1050 \%$ & $735 \%$ \\
\hline Visitas técnicas & $0 \%$ & $0 \%$ & $0 \%$ & $0 \%$ & $15 \%$ & $735 \%$ & $1260 \%$ \\
\hline Atividades de Lazer & $0 \%$ & $0 \%$ & $0 \%$ & $0 \%$ & $15 \%$ & $630 \%$ & $1365 \%$ \\
\hline Destinos Escolhidos & $15 \%$ & $0 \%$ & $0 \%$ & $0 \%$ & $525 \%$ & $15 \%$ & $1365 \%$ \\
\hline Planejar uma experiência no Turismo & $15 \%$ & $0 \%$ & $15 \%$ & $15 \%$ & $15 \%$ & $630 \%$ & $1050 \%$ \\
\hline
\end{tabular}


Revista Científica Digital - Publicidade e propaganda, Jornalismo e Turismo | Junho de 2018

Quadro 1 - Resultados Questão 19 - Grupo que já viajou (conclusão)

\begin{tabular}{|c|c|c|c|c|c|c|c|}
\hline Compreender o sistema do turism॰ & $0 \%$ & $0 \%$ & $15 \%$ & $0 \%$ & $525 \%$ & $420 \%$ & $1050 \%$ \\
\hline Melhorar o conhecimento sobre a disciplina & $15 \%$ & $0 \%$ & $0 \%$ & $315 \%$ & $315 \%$ & $735 \%$ & $630 \%$ \\
\hline Conhecer melhor a realidade do turismo local & $0 \%$ & $0 \%$ & $15 \%$ & $0 \%$ & $210 \%$ & $630 \%$ & $1155 \%$ \\
\hline Desenvolver o pensamento crítico no Turism॰ & $15 \%$ & $0 \%$ & $0 \%$ & $0 \%$ & $15 \%$ & $840 \%$ & $1050 \%$ \\
\hline Desenvolver a liderança em equipe & $15 \%$ & $0 \%$ & $15 \%$ & $630 \%$ & $735 \%$ & $315 \%$ & $210 \%$ \\
\hline Conhecer melhor o que é a realidade profissional turismo & $0 \%$ & $15 \%$ & $0 \%$ & $210 \%$ & $525 \%$ & $735 \%$ & $525 \%$ \\
\hline As experiências me sobrecarregaram de forma excessiva & $1260 \%$ & $15 \%$ & $315 \%$ & $210 \%$ & $210 \%$ & $0 \%$ & $0 \%$ \\
\hline $\begin{array}{l}\text { São importantes na preparação para } \\
\text { a atividade profissional em turismo }\end{array}$ & $0 \%$ & $0 \%$ & $0 \%$ & $15 \%$ & $210 \%$ & $525 \%$ & $1260 \%$ \\
\hline $\begin{array}{l}\text { Ajudam a desenvolver competências } \\
\text { para atuar no mercado em turismo }\end{array}$ & $0 \%$ & $0 \%$ & $0 \%$ & $15 \%$ & $15 \%$ & $1155 \%$ & $735 \%$ \\
\hline Deve-se realizar sempre no curso & $0 \%$ & $0 \%$ & $0 \%$ & $0 \%$ & $0 \%$ & $315 \%$ & $1785 \%$ \\
\hline $\begin{array}{l}\text { Ajudam a compreender melhor a componente } \\
\text { teórico ensinada em sala de aula }\end{array}$ & $0 \%$ & $0 \%$ & $15 \%$ & $15 \%$ & $420 \%$ & $840 \%$ & $630 \%$ \\
\hline $\begin{array}{l}\text { Deve haver um equilibrio entre as componentes } \\
\text { teóricas e as experienciais na carga horária do curso }\end{array}$ & $0 \%$ & $0 \%$ & $0 \%$ & $0 \%$ & $210 \%$ & $945 \%$ & $945 \%$ \\
\hline Considero uma perda de tempo & $20100 \%$ & & & & & & \\
\hline
\end{tabular}

Fonte: Elaborado pelo autor.

\section{Apresentação de dados: grupo que não viajou - Questionário B}

Após a apresentação dos dados do grupo que já realizou viagem, segue, a partir do presente momento, os resultados referentes a aplicação do instrumento junto ao grupo de 20 alunos os quais não realizaram viagens com o curso.

Tabela 10 - Questão 1: Idade

\begin{tabular}{|c|c|c|}
\hline Respostas & Quantidade & Percentual \\
\hline 18 a 21 anos & 06 & $30 \%$ \\
\hline 22 a 25 anos & 10 & $50 \%$ \\
\hline 26 a 30 anos & 02 & $10 \%$ \\
\hline Acima 30 & 02 & $10 \%$ \\
\hline Total & 20 & $100 \%$ \\
\hline
\end{tabular}

Fonte: (O autor, 2017)

Na Tabela 10, foi possível observar que os entrevistados a maioria são jovens de idade, com maior 
incidência (50\%), para jovens entre 22 e 25 anos. O público entre 26 e 30 anos compreende 10\%, o público entre 18 e 21 anos representa $30 \%$ do total e somente $10 \%$ responderam ter a 30 anos ou mais.

Tabela 11 - Questão 2: Em sua opinião, qual a importância das viagens internacionais para a sua formação?

\begin{tabular}{|c|c|c|}
\hline \multicolumn{1}{|c|}{ Resposta } & Quantidade & $40 \%$ \\
\hline Essencial & 08 & $45 \%$ \\
\hline Muito importante & 09 & $15 \%$ \\
\hline Importante & 03 & $0 \%$ \\
\hline Pouco importante & 00 & $0 \%$ \\
\hline Nada importante & 00 & 0.20 . \\
\hline
\end{tabular}

Fonte: Elaborado pelo autor

Na tabela 11, 40\% dos entrevistados afirmaram que as viagens internacionais são essenciais na formação do turismólogo seguido por $45 \%$ achando muito importante, 15\% importante, e nenhum entrevistado respondeu ser pouco ou nada importante.

Tabela 12 - Questão 3: Em sua opinião quais os principais motivos (problemas) que não te permitem viajar com o curso de turismo IPA? (Era possível assinalar mais do que uma resposta)

\begin{tabular}{|c|c|c|}
\hline \multicolumn{1}{|c|}{ Resposta } & Quantidade & $50 \%$ \\
\hline Fator financeiro & 10 & $40 \%$ \\
\hline Fator tempo & 08 & $10 \%$ \\
\hline Não gosta da proposta das viagens do curso & 02 & \multirow{2}{*}{$10 \%$} \\
\hline
\end{tabular}

Fonte: Elaborado pelo autor.

Na tabela 12, o fator financeiro com 50\%, foi apontado como o motivo pelo qual impede o entrevistado de viajar, seguindo com $40 \%$ respondendo como ser o fator tempo, e somente $10 \%$ responderam não gostar da proposta das viagens do curso.

Tabela 13 - Questão 4: Você tem planos de viagem internacional para os próximos 12 meses?

\begin{tabular}{|c|c|c|}
\hline Resposta & Quantidade & Percentual \\
\hline $\operatorname{Sim}$ & 11 & $55 \%$ \\
\hline Não & 09 & $45 \%$ \\
\hline
\end{tabular}

Fonte: Elaborado pelo autor.

Na tabela 13, para 55\% dos entrevistados responderam ter um plano de viagem para 2018 , e $45 \%$ responderam não terem esse plano. 
Tabela 14 - Questão 5: Qual a sua fluência no idioma Inglês?

\begin{tabular}{|c|c|c|}
\hline Resposta & Quantidade & Percentual \\
\hline Nenhuma & 03 & $15 \%$ \\
\hline Básico & 09 & $45 \%$ \\
\hline Intermediário & 05 & $25 \%$ \\
\hline Avançado & 03 & $15 \%$ \\
\hline
\end{tabular}

Fonte: Elaborado pelo autor.

Na tabela 14, com 45\% responderam que sua fluência em inglês é básica, 25\% intermediaria, 15\% não ter nenhuma noção do idioma, e somente $15 \%$ responderam que sua fluência no idioma é avançado.

Tabela 15 - Questão: 6 Qual a sua fluência no idioma Espanhol?

\begin{tabular}{|c|c|c|}
\hline Resposta & Quantidade & $15 \%$ \\
\hline Nenhuma & 03 & $55 \%$ \\
\hline Básico & 11 & $15 \%$ \\
\hline Intermediário & 03 & $15 \%$ \\
\hline Avançado & 03 & \multirow{2}{*}{ Percentual } \\
\hline
\end{tabular}

Fonte: Elaborado pelo autor.

Na tabela 15, com 55\% responderam que sua fluência em espanhol é básica, 15\% intermediaria, 15\% não ter nenhuma noção do idioma, e somente $15 \%$ responderam que sua fluência no idioma é avançado.

Tabela 16 - Questão 7: Você atualmente Trabalha no setor de turismo

\begin{tabular}{|c|c|c|}
\hline Resposta & Quantidade & Percentual \\
\hline Sim & 11 & $55 \%$ \\
\hline Não & 09 & $45 \%$ \\
\hline
\end{tabular}

Fonte: Elaborado pelo autor.

Na tabela 16, verificou-se que mais da metade dos entrevistados 55\%, já trabalham no setor de turismo e $45 \%$ dos respondentes, 5 não trabalhar na sua futura profissão. 
Tabela 17 - Questão 8: Qual a sua faixa salarial média mensal?

\begin{tabular}{|c|c|c|}
\hline Resposta & Quantidade & Percentual \\
\hline Até $\mathrm{R} \$ 1.000,00$ & 05 & $35 \%$ \\
\hline De $\mathrm{R} \$ 1.000,00$ a $\mathrm{R} \$ 1.500,00$ & 07 & $30 \%$ \\
\hline De $\mathrm{R} \$ 1.500,00$ a $\mathrm{R} \$ 2.000,00$ & 06 & $05 \%$ \\
\hline De $\mathrm{R} \$ 2.000,00$ a $\mathrm{R} \$ 2.500,00$ & 01 & $05 \%$ \\
\hline Acima de $\mathrm{R} \$ 2.500,00$ & 01 & \multirow{2}{*}{0} \\
\hline
\end{tabular}

Fonte: Elaborado pelo autor

Na tabela 17, verificou-se que para $30 \%$ dos entrevistados a sua renda é $R \$ 1.500,00$ a $R \$ 2.000,00$, para $5 \%$ responderam ser acima de $R \$ 2.500,00,25 \%$ de até $R \$ 1.000,00,35 \%$ de $R \$ 1.000,00$ a $R \$ 1.500,00$ e $5 \%$ também responderam que sua renda é de $R \$ 2.000,00$ a $R \$ 2.500,00$.

Questão 09, Nas questões abaixo, solicita-se que seja indicado seu ponto de vista sobre a importância das viagens internacionais para sua formação. Para cada pergunta ou item listado, favor pontuar, sendo 1 discordo plenamente e 7 concordo plenamente

Nesse caso, será aplicada a mesma escala de cores para se ilustrar melhor as incidências de respostas.

\section{Nenhuma Incidência}

\section{Uma a cinco incidências}

\section{Seis a dez incidências}

\section{1 a 20 incidências}

Quadro 2 - Resultados Questão 09 - Grupo que não viajou (continua)

\begin{tabular}{|c|c|c|c|c|c|c|c|}
\hline Item & 1 & 2 & 3 & 4 & 5 & 6 & 7 \\
\hline Planejar uma experiência no Turismo & $0 \%$ & $0 \%$ & $0 \%$ & $0 \%$ & $420 \%$ & $420 \%$ & $1260 \%$ \\
\hline Compreender o sistema do turismo & $0 \%$ & $0 \%$ & $0 \%$ & $15 \%$ & $15 \%$ & $420 \%$ & $1470 \%$ \\
\hline Melhorar o conhecimento sobre a disciplina & $0 \%$ & $0 \%$ & $0 \%$ & $210 \%$ & $210 \%$ & $420 \%$ & $1260 \%$ \\
\hline Conhecer melhor a realidade do turismo local. & $0 \%$ & $0 \%$ & $0 \%$ & $0 \%$ & $15 \%$ & $420 \%$ & $1575 \%$ \\
\hline Desenvolver o pensamento crítico no Turismo & $0 \%$ & $0 \%$ & $0 \%$ & $210 \%$ & $210 \%$ & $630 \%$ & $1050 \%$ \\
\hline Desenvolver a liderança em equipe & $0 \%$ & $0 \%$ & $15 \%$ & $420 \%$ & $525 \%$ & $315 \%$ & $735 \%$ \\
\hline Conhecer melhor o que é a realidade profissional turismo & $0 \%$ & $0 \%$ & $15 \%$ & $210 \%$ & $0 \%$ & $735 \%$ & $1050 \%$ \\
\hline
\end{tabular}


Quadro 2 - Resultados Questão 09 - Grupo que não viajou (conclusão)

\begin{tabular}{|c|c|c|c|c|c|c|c|}
\hline As experiências me sobrecarregaram de forma excessiva & $630 \%$ & $210 \%$ & $210 \%$ & $315 \%$ & $420 \%$ & $15 \%$ & $210 \%$ \\
\hline $\begin{array}{l}\text { São importantes na preparação para a } \\
\text { atividade profissional em turismo }\end{array}$ & $0 \%$ & $0 \%$ & $15 \%$ & $0 \%$ & $315 \%$ & $420 \%$ & $1260 \%$ \\
\hline $\begin{array}{l}\text { Ajudam a desenvolver competências } \\
\text { para atuar no mercado em turismo }\end{array}$ & $0 \%$ & $0 \%$ & $0 \%$ & $15 \%$ & $0 \%$ & $630 \%$ & $1365 \%$ \\
\hline Deve-se realizar sempre no curso & $15 \%$ & $0 \%$ & $420 \%$ & $315 \%$ & $210 \%$ & $315 \%$ & $735 \%$ \\
\hline $\begin{array}{l}\text { Ajudam a compreender melhor a componente } \\
\text { teórico ensinada em sala de aula }\end{array}$ & $0 \%$ & $0 \%$ & $0 \%$ & $315 \%$ & $210 \%$ & $630 \%$ & $945 \%$ \\
\hline $\begin{array}{l}\text { Deve haver um equilibrio entre as componentes } \\
\text { teóricas e as experienciais na carga horária do curso }\end{array}$ & $0 \%$ & $0 \%$ & $15 \%$ & $15 \%$ & $210 \%$ & $735 \%$ & $945 \%$ \\
\hline Considero uma perda de tempo & $20100 \%$ & $0 \%$ & $0 \%$ & $0 \%$ & $0 \%$ & $0 \%$ & $0 \%$ \\
\hline
\end{tabular}

Fonte: Elaborado pelo autor

\section{Comparativo entre as respostas de ambos grupos}

Com base nas incidências de respostas apresentadas, foi constatado semelhanças em ambos os grupos em relação a fluência nos idiomas estrangeiros observados na questão 5, tabela 14, No idioma inglês a pesquisa sugere que somente $15 \%$ dos entrevistados que não viajaram dominam o idioma, 70\% responderam que possuem o básico ou intermediário e também 15\% atestam que sua a fluência é nula.

Em relação ao grupo que viajou, $80 \%$ responderam que sua fluência no inglês é básica ou intermediaria, $10 \%$ responderam que sua fluência é nula, e somente $10 \%$ consideram-se fluentes no idioma universal.

No idioma espanhol também não se observou significativas diferenças, pois no grupo que não viajou, 70\% responderam que sua fluência, é básica ou intermediaria, 15\% afirmam que apesar de ter língua espanhola no currículo sua fluência é zero, e apenas $15 \%$ afirmam que falam fluentemente o idioma espanhol.

Já o grupo que viajou, 90\% responderam que sua fluência é básica ou intermediaria, e 5\% afirmaram ser nula a sua fluência e também $5 \%$ responderam serem fluentes neste idioma

Esses indicadores sinalizam para uma realidade na qual o domínio de idiomas não esteja necessariamente atrelado a uma experiência prévia de viagem internacional, sendo este um desafio para todos os turismólogos em formação. O fato de as viagens do curso configurarem como de curta duração (10 a 15 dias) também poderia consistir numa justificativa para o resultado encontrado.

Constata-se ainda semelhanças sobre a atuação no setor de turismo destes futuros turismólogos. Para quem viajou, 50\% responderam que já trabalham no setor de turismo e outros $50 \%$ ainda não atuam no setor. Para o grupo que não viajou, 55\% responderam que trabalham no setor de turismo, enquanto $45 \%$ afirmaram ainda não trabalhar. Essa polarização de respostas identificadas em ambos os grupos poderia evidenciar realidades distintas na profissão, a qual estarão aptos num curto espaço de tempo ou após se formarem.

Quando indagados sobre a importância das viagens internacionais para a sua formação, observaram-se algumas distinções entre os grupos pesquisados. Enquanto no grupo que já viajou, $60 \%$ dos entrevistados alegaram ser essencial a realização destas viagens, no grupo que ainda não viajou esse percentual se reduz a $40 \%$, o que assinala para uma realidade em que as experiências prévia em viagens ao exterior possam servir como um dos principais indutores para os alunos participarem das missões internacionais propostas pelo curso.

Para o grupo que ainda não viajou, quando perguntados, na questão 03 (questionário B) sobre os principais motivos que não permitem viajar com o curso, chama a atenção o fato de que as questões financeiras representaram apenas 50\% 
do total de motivos alegados, enquanto o fator falta de tempo representou $40 \%$, no entanto $10 \%$ dos entrevistados informaram não estar satisfeitos com as propostas de viagens do curso.

Questão semelhante foi aplicada no grupo que já viajou, na questão 04 (questionário $A$ ), com a diferença de que a pergunta buscava saber quais fatores os impedem de viajar mais. Nesse caso, observa-se que a maioria com (95\%) dos entrevistados alega que a falta de recursos seria o principal empecilho indicando que, em se tratando da sua disponibilidade de tempo e de preferências pessoais, as viagens internacionais apareceriam como prioridade.

Acerca dos seus planos futuros de viagens, observam-se consideráveis distinções. Enquanto $70 \%$ dos entrevistados pertencentes ao grupo que já viajou assinala que possui planos para viajar ao exterior nos próximos 12 meses, esse mesmo percentual se reduz para 55\% entre os entrevistados do grupo que ainda não viajou, assinalando que, conforme estas repostas, já se observa que as viagens internacionais façam mais parte dos planos de quem já teve uma experiência prévia dessa natureza.

Foram identificadas igualmente diferenças na faixa salarial entre os grupos. Enquanto no grupo que viajou, $25 \%$ tem a renda mensal média superior a $\mathrm{R} \$ 2.500,00$, este índice cai para um quinto do percentual (apenas 5\%) no grupo que não viajou. Esse indicador assinala para a possibilidade de uma realidade que aponte para maiores oportunidades de remuneração e cargos de liderança a pessoas que já possuem experiência prévia no exterior.

\section{Comparativo entre incidências de cores das respostas das questões 10 (questionário a) e questão 9 (questionário b)}

Figura 1 - Comparativo de incidências de cores entre os grupos

\section{Grupo que não viajou}

\begin{tabular}{|c|c|c|c|c|c|c|c|}
\hline Item & 1 & 2 & 3 & 4 & 5 \\
\hline Planejar uma experiência no Turismo & $0 \%$ & $0 \%$ & $0 \%$ & $0 \%$ & $420 \%$ & $420 \%$ & $1260 \%$ \\
\hline Compreender o sistema do turismo & $0 \%$ & $0 \%$ & $0 \%$ & $15 \%$ & $15 \%$ & $420 \%$ & $1470 \%$ \\
\hline Melhorar o conhecimento sobre a disciplina & $0 \%$ & $0 \%$ & $0 \%$ & $210 \%$ & $210 \%$ & $420 \%$ & $1260 \%$ \\
\hline Conhecer melhor a realidade do turismo local. & $0 \%$ & $0 \%$ & $0 \%$ & $0 \%$ & $15 \%$ & $420 \%$ & $1575 \%$ \\
\hline Desenvolver o pensamento crítico no Turismo & $0 \%$ & $0 \%$ & $0 \%$ & $210 \%$ & $210 \%$ & $630 \%$ & $1050 \%$ \\
\hline Desenvolver a liderança em equipe & $0 \%$ & $0 \%$ & $15 \%$ & $420 \%$ & $525 \%$ & $315 \%$ & $735 \%$ \\
\hline Conhecer melhor o que é a realidade profissional turismo & $0 \%$ & $0 \%$ & $15 \%$ & $210 \%$ & $0 \%$ & $735 \%$ & $1050 \%$ \\
\hline
\end{tabular}

\section{Grupo que já viajou}

\begin{tabular}{|c|c|c|c|c|c|c|c|}
\hline Item & 1 & 2 & 3 & 4 & 5 & 6 & 7 \\
\hline Experiência adquirida & $0 \%$ & $0 \%$ & $0 \%$ & $1-5 \%$ & $15 \%$ & $210 \%$ & $1680 \%$ \\
\hline Contato com outras culturas & $0 \%$ & $0 \%$ & $0 \%$ & $0 \%$ & $210 \%$ & $210 \%$ & $1680 \%$ \\
\hline Amadurecimento Profissional & $0 \%$ & $0 \%$ & $210 \%$ & $15 \%$ & $210 \%$ & $420 \%$ & $1155 \%$ \\
\hline Integração entre colegas & $0 \%$ & $0 \%$ & $15 \%$ & $0 \%$ & $210 \%$ & $1050 \%$ & $735 \%$ \\
\hline Visitas técnicas & $0 \%$ & $0 \%$ & $0 \%$ & $0 \%$ & $15 \%$ & $735 \%$ & $1260 \%$ \\
\hline Atividades de Lazer & $0 \%$ & $0 \%$ & $0 \%$ & $0 \%$ & $15 \%$ & $630 \%$ & $1365 \%$ \\
\hline Destinos Escolhidos & $15 \%$ & $0 \%$ & $0 \%$ & $0 \%$ & $525 \%$ & $15 \%$ & $1365 \%$ \\
\hline Planejar uma experiência no Turismo & $15 \%$ & $0 \%$ & $15 \%$ & $15 \%$ & $15 \%$ & $630 \%$ & $1050 \%$ \\
\hline
\end{tabular}


Conforme as legendas apresentadas nos quadros, quanto maior o destaque da cor de cada item, maior a incidência de resposta do mesmo. Com base, nisso, observa-se em linhas gerais, que existem semelhanças nos itens pesquisados, com diferenças de incidências pouco significativas nas questões assinaladas. Apesar desta semelhança em um panorama geral, alguns pontos receberam consideráveis distinções. $\bigcirc$ de maior destaque é aquele que assinala que as viagens deveriam ocorrer sempre pelo curso. Enquanto 85\% do grupo que já viajou concorda plenamente com esta afirmação, este número cai para 35\% no grupo que ainda não viajou, o que reflete um cenário de que a experiência prévia com viagens no curso promove uma identificação do aluno muito maior com esta modalidade do que aqueles que ainda não possuem esta viagem em seu currículo. Como único item unânime, todos os respondentes de ambos os grupos discordam totalmente de que uma viagem se configuraria em perda de tempo.

Retomando o primeiro objetivo específico proposto para este trabalho, o qual consistia em identificar os principais empecilhos à realização de viagens ao exterior por parte dos estudantes de turismo do IPA, percebe-se que o mesmo foi atingido a partir de um questionário respondido pelos alunos e ex alunos da instituição. Observou-se que os principais motivos para o grupo que já viajou remontam, prioritariamente para questões financeiras. Já para os alunos que não viajaram, observa-se uma maior polarização entre a falta de recursos financeiros e a falta de tempo.

Retomando o segundo objetivo específico para este trabalho, o qual consistia em apresentar e analisar pontos de semelhanças e diferenças de perfil entre os dois grupos de entrevistados sob as categorias domínio de idiomas, colocação no mercado, faixa salarial e planejamento pessoal de viagens futuras, percebe-se que o mesmo foi atingido a partir da análise do levantamento dos dados de cada entrevistado, em especial nas questões que pontuavam estes mesmos temas. Em uma análise geral, percebe-se poucas distinções entre as variáveis domínio de idiomas e colocação no mercado, apresentando índices de respostas semelhantes, o que evidencia que os desafios nesses quesitos são pertinentes a todos os grupos de profissionais em turismo. Já as maiores diferenças foram observadas em faixa salarial, em que se identificou que os respondentes que já viajaram em geral, estão tendo acesso a melhores remunerações e no planejamento pessoal de viagens futuras, em que o percentual de pretensões de viagens para o grupo que viajou supera em 15\% o grupo que não viajou. Ficou igualmente claro através dos dados coletados, que ambos grupos confirmam a importância das viagens para a formação do Turismólogo com 85\% essencial ou muito importante.

\section{Conclusão}

Este trabalho teve como objetivo verificar a importância das viagens internacionais na formação dos futuros profissionais do turismo, analisar a relevância dos discentes no quesito viagens, e os que não tiveram esta oportunidade. $\bigcirc$ atingimento dos objetivos foi baseado nas respostas recebidas via questionário pelos 40 alunos e ex alunos de graduação em Turismo pelo Centro Universitário Metodista, IPA.

Com a realização desta pesquisa e do conhecimento adquirido, foi possível notar que os autores abordados retratam a importância das viagens internacionais na sua formação, além de trazer vários benefícios como compreensão sobre novas culturas e mais conhecimento sobre o turismo em si, e fazer um turismo com eficiência, qualidade e dinamismo.

Acerca da pesquisa, foi possível analisar que embora as viagens internacionais sejam muito importante para a formação dos futuros profissionais do turismo, muitos deles ainda tiveram essa oportunidade por inúmeros motivos, em especial, por questões relativas a tempo e recursos financeiros.

Entre um comparativo dos grupos, observou-se que existem maiores semelhanças no perfil dos respondentes no tocante as categorias: domínio de idiomas e colocação no mercado de trabalho, assinalando que estas variáveis, em tese, independeriam diretamente das experiências (de curta duração) no exterior. As maiores distinções foram observadas nas categorias de faixa salarial e planejamento pessoal de viagens futuras, assina- 
lando que o grupo que já viajou possui, em geral, melhor faixa de remuneração e maior perspectiva de realização de novas viagens internacionais no período de 01 ano. Estas duas últimas incidências de diferenciações entre profissionais possuem traços que assemelham-se aos dos jovens que realizavam o Grand Tour, os quais, segundo o referencial de Barretto (2006) e Barbosa (2005), retornavam de suas viagens com maior visibilidade em suas profissões e, consequentemente, maior acesso a melhores oportunidades de cargos e remuneração.

Quanto à existência de estímulos específicos com a finalidade de atrair os alunos para participarem das viagens internacionais, percebe-se que os entrevistados estão satisfeitos em relação aos destinos escolhidos, a forma democrática como é fei- to, e a totalidade acredita que é necessário a continuação e implementação das viagens por acharem muito importante para a obtenção do diploma.

Fica evidenciado portanto, a importância das viagens internacionais na formação do Turismólogo, pois apesar das agências de turismo serem apenas um dos pilares do formando, pois suas atribuições são várias. Este modo de conhecimento de novas culturas, lugares e pessoas representa segundo os entrevistados a grande importância na sua formação, pois mais de $80 \%$ afirma, que a experiência adquirida faz diferença na hora de trabalhar com turismo.

O pesquisador sugere que no futuro haja um aprofundamento no estudo de caso, para uma maior compreensão dos resultados aqui apresentados. 


\section{Referências}

AVENA, Biaggio Mauricio. Por uma pedagogia da viagem, do turismo e do acolhimento: itinerários pelos significados e contribuições das viagens a (trans)formação de si. 2008. 516p. Tese (Doutorado em Educação), Faculdade de Educação, Universidade Federal da Bahia, Salvador, 2008.

BARBOSA, Ycarim Melgaço. História das Viagens e do Turismo. 2 ed. Revista. São Paulo: Aleph, 2005.

BARRETTO, Margarita. Manual de iniciação ao estudo do turismo. 15.ed. Campinas: Papirus, 2006.

BENI, Mario Carlos. Análise Estrutural do Turismo. $4^{a}$ ed. rev. São Paulo: Editora SENAC São Paulo, 2001. p. 427

BRASIL, Ministério do Turismo. Turismo de Estudos e Intercâmbio: Orientações Básicas. $2^{\circ}$ Edição. Brasília: Ministério do Turismo, 2010.

BRIDI, Guilherme, SANTOS, Marcia. Formação e atuação do turismólogo no cenário das agências de turismo. Contrapondo competências. Porto Alegre. EdiPUCRS, 2012

BRIDI G, PRISCO B, VIERA EVD Foreign Students and Their Perception on the Elements of Urban Mobility and Hospitality: A Comparative Study in the Cities of Boston and Porto Alegre. J Tourism Hospit 7: 335. 2018 doi: 10.4172/2167-0269.100033

DENCKER, Ada. F. M. Pesquisa em turismo: planejamento, métodos e técnica. São Paulo: Futura, 20037

GIL, Antônio Carlos. Como elaborar projetos de pesquisa. 4. Ed.-9. reimpressão - São Paulo: Atlas, 2007.

GODOY, Arilda S. Introdução à pesquisa qualitativa e suas possibilidades. Revista de Administração de Empresas, v.35, n.2, Mar./Abr., p. 57-63, 1995,

MINAYO, M. C. de S.; DESLANDES, S. F.; GOMES, R. Pesquisa Social: teoria, método e criatividade. 26. ed. Petrópolis, RJ: Vozes, 2007.

PILATTI, Andriele, SANTOS, Maria Elisabete. O domínio da língua inglesa como um fator determinante para o sucesso profissional no mundo globalizado. Secretariado Executivo em Revista. Universidade de Passo Fundo. Passo Fundo - RS, n. 4, 2008,

REJOWSKI, Mirian et al. Desenvolvimento do Turismo. In: REJOWSKI, Mirian (org.) Turismo no percurso do tempo. 2 ed. São Paulo: Aleph, 2005.

SILVA, Stella Maris Wolff. Cooperação acadêmica internacional da Capes na perspectiva do Programa Ciência sem Fronteiras. Dissertação de Mestrado UFRGS, 2012.

SODRE, João Clark. Arquitetura e Viagens na formação pelo Brasil 1938-1962 - São Paulo, 2010.

SOUZA, Raul j. Viagens Tecnicas: Instrumentos Potenciais De Aprendizagem Nos Cursos Superiores De Tecnologia De Turismo No Brasil. São Paulo. s/a

YIN, Robert K. Estudo de Caso: Planejamento e Métodos. 3. ed. - São Paulo: Bookman, 2010. 